\title{
Identidade e trabalho: considerações sobre as relações identitárias no mundo do trabalho porto-aleorense (1896-1920)
}

Isabel Bilhão*

\begin{abstract}
Resumo: O presente texto tem o propósito de refletir sobre o instrumental teórico-metodológico utilizado em minha tese de doutorado, na qual objetivei analisar o processo de construção identitária dos operários porto-alegrenses no final do século XIX e primeiras décadas do século XX, partindo de três hipóteses norteadoras: 1) A construção da identidade operária tem como um de seus fundamentos a busca de reconhecimento através do orgulho de sua capacidade produtiva; 2) As identidades sociais existem sempre em relação umas com as outras, influenciando-se mutuamente e contribuindo para que ocorram permanentes transformações identitárias; 3) A identidade operária é construída não apenas a partir das peculiaridades do local e do contexto em que se encontram os trabalhadores, mas também da conjugação dessas peculiaridades com idéias, símbolos e características que aparecem em diversos lugares e circulavam em diferentes países.
\end{abstract}

* Doutora em História pela UFRGS. Professora do Departamento de História e Geografia da UCS.

Anos 90, Porto Alegre, v. 13, n. 23/24, p.215-240, jan./dez. 2006 
Identidade e trabalho: considerações sobre as relações...

Palavras-chave: relações identitárias - trabalho - identidade operária.

O principal objetivo deste texto é refletir sobre o instrumental teórico-metodológico que embasou minha investigação sobre o processo de construção da identidade dos operários portoalegrenses na virada e primeiras décadas do século $\mathrm{XX}^{1}$. O ponto de partida dessa reflexão foi a procura por pensar esse processo tanto a partir da superação de uma visão determinista das estruturas sociais em relação aos grupos e indivíduos, quanto a partir de uma visão que privilegiasse a interação entre os sujeitos sociais que contracenam e negociam diariamente com outros indivíduos e grupos dentro da sociedade na qual estão inseridos.

Engajei-me, assim, a uma opção historiográfica que vem conquistando cada vez mais importância nas pesquisas sobre o mundo do trabalho, na qual a história operária deixou de ser unicamente a história do movimento operário organizado, onde os sindicatos, partidos e correntes ideológicas deixaram de ocupar sozinhos o centro das preocupações e passaram a compartilhar espaços cada vez maiores com a análise das condições de existência diárias e das relações cotidianas do operariado.

Essa opção liga-se a uma visão da história do mundo do trabalho que deve muito aos estudos de E. P Thompson ${ }^{2}$. Reconhecidamente, ele é um dos primeiros historiadores a buscar romper com determinismos economicistas e estruturalistas até então predominantes nessa área de investigação, criticando uma noção simplista do conceito de classe operária, vinculada a uma tradição presente tanto nos estudos acadêmicos, tributários de um viés estruturalista do marxismo, quanto no movimento comunista europeu (Thompson, 1979, p. 13-61).

Das reflexões formuladas por Thompson, três interessaram especialmente a minha análise. Primeiramente, a de que no interior da classe operária existem homens e mulheres que, em suas relações de produção, convivem com uma cultura e expectativas 
herdadas, ao mesmo tempo em que moldam essas experiências em novas formas culturais (Thompson, 1987, V. I, p.10). Isto é, a percepção do caráter dinâmico da experiência, do "fazer-se classe", que ocorre a partir da interação de inúmeros fatores, dentre eles: as tradições políticas, os costumes de trabalho, a formação religiosa, a divulgação de idéias através de textos de diversos pensadores, a legislação ou o combate a ela (Thompson, 1987, V. II, p. 18).

Em segundo lugar, sua concepção de que a consciência de classe não pode ser analisada separada do processo histórico do fazer-se classe, pois é nele que, dinamicamente, o conjunto dos trabalhadores, enquanto faz-se classe, adquire consciência disso. Dessa forma, segundo Thompson, "a classe acontece quando alguns homens, como resultados de experiências comuns (herdadas ou partilhadas), sentem e articulam a identidade de seus interesses entre si, e contra outros homens cujos interesses diferem (e geralmente se opõem) dos seus" (Thompson, 1987, V. II, p. 10).

Finalmente, a idéia de que a classe operária forma-se e é formada em diversos "campos de batalha". Assim, se por um lado, é necessário pensá-la de forma distinta e em oposição aos interesses dos patrões; por outro, os trabalhadores também buscarão se diferenciar das classes inferiores ou "perigosas" afastando-se de seu mundo de miséria, doenças e insegurança. Desse modo, a consciência da classe operária, que se constrói no enfrentamento e na percepção da exploração em relação às classes superiores, também irá se construir a partir da diferenciação em relação às classes subalternas, com as quais os operários não querem ser confundidos (Thompson, 1987, V. III, p. 418-419).

Da leitura dessas proposições, surgiram algumas inquietações que motivaram minha investigação; dentre elas, destaca-se a percepção de que a dinâmica do fazer-se classe e, ao mesmo tempo, ir se percebendo como tal é perpassada por um processo de construção identitária dos operários que estabelecem critérios e estratégias de reconhecimento e distinção, o que significa dizer 
Identidade e trabalho: considerações sobre as relações...

que a construção da consciência de pertencimento a uma classe é indissociável da percepção identitária que os operários constroem entre si e em relação às outras classes sociais.

Essa reflexão teórica motivou-me a tentar compreender como ocorreu, no interior do mundo do trabalho porto-alegrense, o processo de construção identitária dos operários que, no final do século XIX e inícios do século XX, viveram nessa cidade, estabelecendo em relação aos seus "iguais" e em relação aos "outros" laços de solidariedade, reconhecimento, distinção e oposição.

O interesse por analisar a questão dentro desse marco cronológico decorreu do fato de que, nesse período, Porto Alegre foi marcada por uma transformação no processo e nas relações de trabalho caracterizada pela paulatina redução do número de artífices especializados e de oficinas artesanais que passaram, pouco a pouco, a dar lugar às fábricas, permitindo, ao mesmo tempo, o surgimento da atividade de operário e sua valorização social, fazendo com que o antigo orgulho de ofício começasse a ceder lugar a uma nova conduta: a de pensar-se coletivamente, postulando progressivamente não mais a valorização da técnica e do saber individuais, mas o pertencimento a uma coletividade de operários.

Nesse contexto, a cidade cresceu tanto do ponto de vista econômico quanto demográfico e se transformou urbanisticamente, passando a conviver com uma incipiente organização operária marcada por agitações, prisões e destaque de lideranças de diferentes tendências ideológicas, evidenciando-se disputas, posições de reconhecimento e distinção, nas quais se percebem características do processo de construção da identidade operária em interrelação com outras identidades coletivas, como as étnicas e as de gênero.

Assim, o eixo analítico de meu estudo é a busca do entendimento de como, no interior de todas essas transformações, os operários porto-alegrenses construíram suas relações identitárias, 
Isabel Bilhão

vistas como um fator indissociável de sua construção/reconhecimento como classe.

Algumas das reflexões realizadas em meu trabalho apoiaramse na obra Culturas de Classe: identidade e diversidade na formação do operariado, que apresenta uma coletânea de artigos de historiadores, sociólogos e antropólogos, brasileiros e estrangeiros dedicados a um amplo panorama dos estudos históricos da "cultura operária", entendida, segundo os organizadores, "mais como um campo de discussão do que propriamente como um conceito" (Batalha; Silva; Fortes, 2004, p. 12).

Das várias abordagens apresentadas, chamaram-me a atenção as discussões que animam o debate teórico sobre a história do trabalho inglesa, tratadas nos textos de Mike Savage e Nevilie Kirk que discutem a tensão entre os elementos integradores e desintegradores da experiência de classe, apresentando, por um lado, as visões da classe operária como "totalidade cultural consolidada, com práticas, símbolos e instituições claramente diferenciadas" e, por outro, como fruto do "processo marcado pela multiplicidade de experiências, pela flexibilidade dos costumes e pela circulação de valores".

É em meio a essa tensão que, em meu entendimento, deve ser analisada, em diferentes contextos e escalas, a construção da identidade operária, tendo em mente que "tanto elementos sociais e culturais desagregadores quanto estratégias de resolução ou atenuação dos conflitos em busca de unidade fazem parte das experiências vividas pelas coletividades operárias" (Batalha; Silva; Fortes, 2004, p. 12).

Nesse sentido, o artigo de Mike Savage questiona "inclinações reducionistas" tanto das visões economicistas quanto das que levam em consideração apenas o mercado de trabalho na análise da classe operária e aponta para a necessidade de um aporte analítico mais complexo, voltado especialmente para a "formação da classe", no qual não se procure uma "base estrutural precisa para 
Identidade e trabalho: considerações sobre as relações...

as relações de classe", e que se olhe mais "para as estratégias de vida atualizadas nos bairros urbanos e nos lares" do que "para o processo de trabalho em si mesmo".

Segundo essa proposição, o traço distintivo da vida operária não se apóia exclusivamente no processo de trabalho, mas, especialmente para aqueles que não fazem parte de uma "aristocracia operária", na "insegurança estrutural" vivida pelos trabalhadores nas sociedades capitalistas. Para Savage, essa formulação ajuda a superar reducionismos, uma vez que, por um lado, o dado básico da insegurança não implica nenhuma forma específica de desdobramento na consciência de classe ou na política expressa pelos trabalhadores e também não implica união do operariado, em detrimento de rivalidades internas. Mas, por outro, "reforça a necessidade de olhar para os fatores contextuais que explicam como a própria carência geral dos trabalhadores em lidar com tal insegurança conduz a diferentes tipos de resultados culturais e políticos" (Savage, 2004, p. 33).

Seria, portanto, o primado da análise das peculiaridades locais $^{3}$ e conjunturais na formação da classe operária, em detrimento de um modelo estruturalista. Perspectiva reforçada no artigo de Neville Kirk, especialmente por sua preocupação em demonstrar que "elementos tanto de diversidade e semelhança quanto de divisão e unidade coexistem entre os trabalhadores", e que esses só podem ser pensados "nos seus contextos históricos totais e cambiantes", levando-se em consideração que "nem a classe trabalhadora, nem qualquer outra classe social será jamais um ente completamente unido e indiferenciado, fixo e congelado no tempo" (Kirk, 2004, p. 52-53).

Em âmbito nacional, Emilia Viotti da Costa, ao elaborar, no final dos anos 1990, um balanço sobre os estudos em história social, mostrava-se preocupada com o risco da fragmentação que uma visão voltada apenas às especificidades locais poderia causar a este campo de investigação e alertava para o fato de que, se os 
Isabel Bilhão

historiadores optassem por uma visão que privilegiasse apenas o estudo dos pequenos grupos (trabalhadores, vizinhanças, tribos de jovens, etc.), poderiam cair na tentação de criar "ilhas alternativas de cultura", oferecendo apenas "uma compilação não-crítica de detalhes, cuja relevância não é questionada", "um cemitério de fontes ou um museu de curiosidades" (Costa, 1998, p. 17).

Por outro lado, Viotti da Costa evidenciava seu otimismo quanto às possibilidades de realização de sínteses que poderiam evitar "todas as formas de reducionismos e de reificação, seja eco-

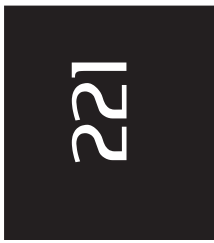
nômico, cultural ou lingüístico", propondo que os estudos em história social procurassem não perder de vista "a articulação entre a micro e a macro-física do poder, [...] que reconhecesse[m] que a subjetividade humana é ao mesmo tempo constituída por e constituinte de realidades sociais" (Costa, 1998, p. 20).

Assim, ao analisar a construção da identidade operária em um determinado contexto e local, penso ser necessário levar em conta as duas preocupações expressas nos textos anteriormente mencionados, ou seja, não se pode, por um lado, perder de vista os particularismos da esfera local com suas peculiaridades e desdobramentos e, por outro, deve-se observar que uma construção identitária não ocorre de forma isolada, tanto no que diz respeito à sociedade na qual está inserido o grupo de identidade quanto, em um contexto mais amplo, à época e aos acontecimentos nacionais e internacionais que, em diferentes medidas, lhe dizem respeito, procurando combinar, dessa forma, as esferas micro e macrológicas de análise.

Para dar conta da complexidade dessa análise, os historiadores têm recorrido freqüentemente a outras áreas de estudo, notadamente a Antropologia e a Sociologia. Foram os antropólogos e os sociólogos que, ao fazerem incursões pelo campo da História, demonstraram inicialmente as possibilidades e riquezas das análises, que mesmo não abrindo mão de uma explicação macrosocial, pensassem os sujeitos reais em suas vivências cotidianas. 
Identidade e trabalho: considerações sobre as relações...

Assim, esse enfoque, que entrecruza os olhares dessas diferentes áreas do conhecimento, vem demonstrando aos historiadores do mundo do trabalho, cada vez mais, a necessidade de estudar a classe a partir não apenas do locus da produção, mas também em seus ambientes de moradia e sociabilidade e trabalhar com noções como as de cultura, tradição, costumes e comunidade.

É nesse âmbito de discussões que o estudo da construção da identidade operária tem encontrado terreno fértil para ampliar e aprofundar suas análises, priorizando as noções de experiência identitária e a percepção de que a identidade operária é construída e se constrói de forma inter-relacional com outras identidades coletivas, a partir tanto de peculiaridades locais quanto de macro influências.

Entretanto, conforme constatou o sociólogo Stuart Hall, analisando diferentes concepções acerca da identidade, esse é um conceito "muito complexo, pouco desenvolvido e mal compreendido na ciência social contemporânea" (Hall, 1998, p. 8). Tal dificuldade de compreensão pode estar ligada, como escreve Hall, entre outros motivos, ao fato de que uma identidade "totalmente segura, completa, unificada e coerente é uma fantasia muitas vezes embasada em narrativas construídas a posteriori, que permite aos grupos sentirem-se seguros e reconfortados" (Hall, 1998, p. 17). Dito de outra maneira, deve-se ter em mente, ao estudar a construção das identidades coletivas, que elas são sempre construções fluidas e cambiantes, nas quais não se pode encontrar algo como um "núcleo duro", um "caroço" essencial e imutável, mesmo que muitas vezes o grupo identitário tenda discursivamente à unificação e ao essencialismo e busque a construção de uma memória livre de contradições.

Lidar com toda essa dinâmica constitui uma matéria extremante complexa, por esse motivo, pareceu-me inevitável recorrer novamente à contribuição de outros campos de estudo, notadamente a Sociologia e a Antropologia, para procurar definir 
os referenciais com os quais busquei analisar a construção da identidade coletiva dos operários porto-alegrenses.

Nesse caso, uma primeira questão diz respeito ao fato de que, quando se fala em identidades coletivas, não se pode esquecer que não existe uma separação, uma linha divisória clara e estabelecida entre as identidades pessoal e social. Esse alerta é feito pelo antropólogo Roberto Cardoso de Oliveira, no clássico Identidade, etnia e estrutura Social, onde ele trabalha com a proposição de que "a identidade social não se descarta da identidade pessoal, pois esta também de algum modo é um refluxo daquela" (Oliveira, 1976, p. 5). Para ele,

[...] a identidade é um fenômeno que emerge da dialética entre indivíduo e sociedade. Sendo formada por processos sociais e, uma vez cristalizada, é mantida, modificada, ou, mesmo, remodelada pelas relações sociais [...], dessa forma o conceito de identidade social ou coletiva está diretamente relacionado à noção de experiências ou de 'relações de identidade' (Oliveira, 1976, p. 44).

Penso que essa proposição pode ser aproximada das idéias mais recentemente formuladas pelo antropólogo português José Manuel Oliveira Mendes de que "[...] a identidade é socialmente distribuída, construída e reconstruída nas interações sociais. As identidades serão, assim, construções relativamente estáveis num processo contínuo de atividade social" (Mendes, 2002, p. 504). Isso significa que, conforme Mendes, "o indivíduo forma sua identidade não da reprodução pelo idêntico oriunda da socialização familiar, do grupo de amigos, etc., mas sim do ruído social, dos conflitos entre os diferentes agentes e lugares de socialização". Portanto, para esse autor, a identidade social é vista como "um cruzamento de atributos pessoais e estruturais" e como 
Identidade e trabalho: considerações sobre as relações...

[...] uma tentativa permanente por parte do indivíduo de integração da multiplicidade de pertenças sociais e papéis a que está submetido. A busca do reconhecimento, da honra, é contínua, procurando o indivíduo redes de reconhecimento mútuo. Os participantes nessas redes procuram criar ideologias comuns, histórias comuns, que integrem e legitimem suas ações (Mendes, 2002, p. 505-509).

Logo, cabe esclarecer que, ao analisar a construção da identidade operária porto-alegrense, optei por um enfoque que privilegiou a noção de experiência identitária, na qual a interação das vivências pessoais e sociais, em seus múltiplos papéis e pertenças, precisou ser considerada de forma relacional.

Para contemplar esse enfoque, utilizei um instrumental analítico que priorizou três aspectos da construção identitária: o reconhecimento, a distinção e a memória coletiva. Nesse caso, o reconhecimento foi pensado a partir das relações estabelecidas pelo sociólogo Pierre Bourdieu, tomadas de empréstimo de sua análise sobre a importância da identidade na construção e utilização da idéia de região. Para Bourdieu, a identidade é um "ser percebido que existe fundamentalmente pelo reconhecimento dos outros". Entretanto,

[...] o efeito de reconhecimento que o fato da objetivação no discurso exerce não depende apenas do reconhecimento consentido àquele que o detém; ele depende também do grau em que o discurso, que anuncia ao grupo sua identidade, está fundamentado na objetividade do grupo a que ele se dirige, isto é, no reconhecimento e na crença que lhe concedem os membros deste grupo assim como nas propriedades econômicas ou culturais que eles têm em comum (Bourdieu, 1989, p. 117).

No caso de minha análise, a importância de tal proposição encontra-se no entendimento de que para haver a aceitação da

Anos 90, Porto Alegre, v. 13, n. 23/24, p.215-240, jan./dez. 2006 
validade do discurso identitário - ou da liderança daquele que o profere - é preciso que o grupo de identidade tenha condições objetivas de reconhecimento dessas características unificadoras, que seriam, por exemplo, o pertencimento a um mesmo local de trabalho (ou ao grupo operário), a freqüência aos divertimentos "tipicamente" operários, a utilização de símbolos identificadores em momentos de apresentação pública da coletividade operária, etc.

Isso significa que o reconhecimento demanda ações práti-

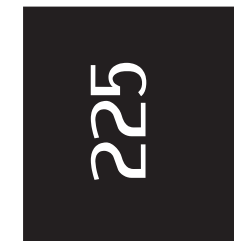
cas, operações de pertencimento que podem definir a aceitação ou exclusão de um determinado membro do grupo. Em um estudo na área da Psicologia Social, Antonio da Costa Ciampa chama a atenção justamente para as condições objetivas de reconhecimento, que estabelecem os fatores de aceitação do indivíduo em seu grupo de identidade, salientando a existência de uma "expectativa generalizada de que alguém deve agir de acordo com o que é (e conseqüentemente ser tratado como tal), reatualizando através de rituais sociais uma identidade pressuposta que assim é reposta" (Ciampa, 1985, p. 66).

Mas, além do reconhecimento, a distinção é outra característica importante na construção das identidades coletivas. Pierre Bourdieu, no texto anteriormente citado, também coloca a distinção como um fator decisivo nas construções identitárias; segundo ele, "o mundo social é representação e vontade, e existir socialmente é também ser reconhecido como distinto" (Bourdieu, 1989, p. 118).

Essa distinção, de acordo com Bourdieu, por vezes ocorre pela via da estigmatização de comportamentos, vivências e hábitos. Entretanto, a própria estigmatização pode vir a ser um dos fatores constitutivos da identidade grupal, quando "o estigma produz a revolta contra o estigma, que começa pela reivindicação pública do estigma, constituindo assim um emblema [...] que termina na institucionalização do grupo constituído que sofre os 
Identidade e trabalho: considerações sobre as relações...

efeitos econômicos e sociais da estigmatização" (Bourdieu, 1989, p. 129).

Essa proposição, observada à luz do que examinei na tese, pôde ser pensada, por exemplo, a partir da apropriação do estigma do demérito do trabalho braçal por parte dos operários, que passam a reivindicá-lo como um valor positivo, através da idéia de que o trabalho constrói a riqueza da sociedade e de que aqueles que o exercem merecem respeito, transformando-se em um importante emblema de reconhecimento, ajudando na construção de sua identidade coletiva.

Portanto, a dinâmica relação de pertencer a um grupo em oposição ou diferenciação aos outros também indica o lugar no mundo ocupado pelos indivíduos. Ao estudar os imaginários sociais, o historiador polonês Bronislaw Baczko propôs que é através deles que uma coletividade define suas distinções, pois "[...] elaborando uma representação de si mesma; marca a distribuição dos papéis e as posições sociais, expressa e impõe certas crenças comuns". Assim, para Baczko, designar uma identidade coletiva consiste em delimitar um "território" e as fronteiras deste; definir suas relações com os outros; formar imagens de amigos e inimigos, de rivais e aliados; do mesmo modo, significa selecionar, conservar e modelar as lembranças do passado, assim como projetar para o futuro seus temores e esperanças (Baczko, 1991, p. 28).

Com isso chego ao terceiro elemento com o qual analisei a construção da identidade operária - a memória. Nesse caso, recorri às análises do sociólogo Michael Pollak, especialmente a sua proposição de que a valorização dos acontecimentos dos quais as pessoas nem sempre participaram faz com que esses ganhem força no imaginário de um grupo e se transformem em eventos comuns, socializados política ou historicamente, gerando a identificação dos indivíduos com um determinado passado, com uma memória herdada que serve, inclusive, para marcar distinções históricas com 
outros grupos, reforçando e justificando as relações de identificação e de oposição vivenciadas no presente (Pollak, 1992, p. 201).

Portanto, a construção identitária dos operários portoalegrenses é pensada aqui a partir de suas relações de reconhecimento e distinção, bem como pela reivindicação de uma memória comum herdada que reforça e justifica, no presente, a delimitação de "territórios" sociais e o estabelecimento de alteridades.

Estabeleci como primeira hipótese norteadora dessa análise a de que a construção da identidade operária passa pela "autoestima no trabalho" (Thompson, 2001, p. 258-260), pela busca do reconhecimento e da valorização do grupo através do orgulho de sua capacidade para o trabalho - inclusive pela apropriação do estigma de "trabalhadores braçais" que é transformado em emblema.

Essa reivindicação de reconhecimento implica também que os operários se distingam tanto dos "exploradores capitalistas" e das "classes perigosas" - aqueles que se encontram fora do mundo produtivo, indigentes e/ou delinqüentes ou que vivem de forma considerada desonrosa pela moral predominante no período, da prostituição, por exemplo, ${ }^{4}$ - quanto da imagem construída pelo discurso dominante, que os associa ao vício, à preguiça e à indisciplina sempre que eles ameaçam sair do controle e/ou reivindicam melhores condições de vida e trabalho.

A segunda hipótese dessa análise é a de que as identidades coletivas não existem de forma isolada umas das outras. Dessa forma, a identidade operária só pode ser pensada a partir da relação, convivência ou conflito com outras identidades que interagem em sua construção, contribuindo para uma constante e recíproca transformação e reelaboração.

Finalmente, a terceira hipótese norteadora de minha investigação foi a de que a construção identitária dos operários passa pela apropriação/invenção de símbolos e de uma memória historicamente herdada, que reafirmam seus sentimentos de pertença e 
Identidade e trabalho: considerações sobre as relações...

distinção, não apenas em âmbito local, mas de forma integrada a um sentimento de contemporaneidade e simultaneidade com o operariado internacional - seus conflitos, contradições, campanhas - auxiliando na formação de uma identidade coletiva que ultrapassa barreiras geográficas.

Portanto, optei por tratar de uma perspectiva da história do movimento operário porto-alegrense, não privilegiando uma sucessão cronológica, mas sim trabalhando com recortes temáticos e com problemáticas cujo eixo norteador foi a análise da construção identitária desses operários. Por exemplo: os modelos de conduta propostos pelas lideranças, visando demarcar as diferenças em relação aos exploradores capitalistas e às "classes perigosas", as interfaces entre as identidades operária, étnica e de gênero; a circulação de pessoas, textos, idéias e campanhas que permitiram perceber as inter-relações entre as peculiaridades locais e o contexto nacional e internacional em que estavam inseridos os operários e, finalmente, os rituais operários - como as comemorações do Primeiro de Maio - e os símbolos de reconhecimento internacionalmente utilizados, que foram vistos como elementos de uma memória operária herdada.

Estou ciente, entretanto, de que essa opção traz consigo algumas dificuldades inerentes ao tipo de "olhar" lançado às fontes: a primeira - e talvez a mais séria - seja a tendência em ver "identidade" em tudo, isto é, dada à amplitude da discussão que envolve o assunto, um dos perigos que cercam sua abordagem é tender à constatação de que qualquer faceta do discurso operário pode indicar uma característica identitária. Uma forma de tentar evitar esse risco foi retornar sempre aos referenciais teóricos do trabalho.

Outro problema que pode acometer uma pesquisa como esta é o de se tentar padronizar os discursos identitários, esquecendose que eles são permeados por conflitos, disputas e distintas informações ideológicas que se conjugam tanto no interior do grupo 
operário quanto em sua relação com o restante da sociedade. Assim, foi novamente o diálogo entre o referencial teórico e a análise empírica que contribuiu para evitar essa outra armadilha.

Quanto à análise empírica, utilizei-me principalmente de fontes jornalísticas. No que diz respeito a elas, estou ciente de que parti, no caso das publicações operárias e das "colunas operárias" dos jornais comerciais, do ponto de vista de um grupo de lideranças - ou nem tanto - que compunham o que se poderia chamar de "os de cima" do movimento operário, aqueles que tinham acesso a alguma forma de instrução, ao trabalho na imprensa (que lhes facilitava a veiculação de idéias), à circulação nos meios intelectuais, políticos e artísticos da cidade e que, portanto, formavam uma pequena parte, muitas vezes distinta, do conjunto do operariado (Batalha, 1997, p. 93). Assim, os textos publicados nos jornais operários só permitiram chegar muito indiretamente às formas de constituição de uma identidade operária, pois, na maioria dos casos, mostravam muito mais os projetos das lideranças do caminho a ser trilhado pelo conjunto dos trabalhadores do que a realidade da vida cotidiana. Também não se pode perder de vista que esses textos são marcados por disputas ideológicas pela direção dos rumos da organização operária (Bilhão, 1999, p. 77-109).

Os veículos analisados nessa investigação podem ser divididos em quatro categorias. Inicialmente, os jornais operários, nesse caso, A Democracia, periódico socialista que circulou de 1905 a 1907. Segundo Benito Schmidt, esse jornal amparava-se "em um discurso messiânico, cabendo ao litógrafo Xavier da Costa o papel de 'apóstolo', líder de um grupo votado ao sacerdócio em prol da difusão de nobres ideais" (Schmidt, 2002, p. 269); seu sucessor, o também socialista, Avante, que circulou durante o ano de 1908 e A Luta, veículo dos militantes anarquistas, analisado em sua primeira fase (de 1906 a 1911), contando, como principais editores, com Polydoro dos Santos (gráfico), Henrique Gomes Ferro (médico), Henrique Martins (Cecílio Vilar - gráfico), Stefan Michalski 
Identidade e trabalho: considerações sobre as relações...

(marmorista e alfaiate), Reynaldo Frederico Geyer (médico) e José Rey Gil (gráfico) (Aravanis, 2002, p. 268). Uma preocupação constante desses periódicos era a de "informar" para "formar", definindo posturas e características a serem seguidas ou evitadas, bem como explicando o que é socialismo e o que é anarquismo; para isso recorriam a falas de autoridades, traduções e vulgarizações de textos publicados no exterior e em outros estados e explicações didáticas feitas por articulistas locais.

$\mathrm{Na}$ segunda categoria, encontram-se os jornais comerciais que possuíam entre seus redatores militantes ou simpatizantes do movimento operário, como é o caso da Gazetinha (analisada no período de 1897 e 1898), de propriedade de Octaviano Manoel de Oliveira, contando com a colaboração de Francisco Xavier da Costa e tratando, em vários momentos, das "questões operárias"; o Echo do Povo (analisado de 1908 a 1914), veículo onde Xavier da Costa trabalhou como Redator-Chefe a partir de 1911, cujo proprietário, Antônio Heit, era antigo colaborador deste líder socialista n' $A$ Democracia; o Petit Journal (analisado de 1905 a 1907), periódico literário que contava com o socialista Carlos Cavaco como secretário-geral, e O Diário (analisado de 1912 a 1914), no qual Polydoro dos Santos trabalhava como redator.

$\mathrm{Na}$ terceira categoria, estão os jornais comerciais que se apresentavam como "órgãos independentes", ou seja, que não pertenciam ao Governo do Estado ${ }^{5}$ e nem a algum grupo ideologicamente identificado, como é caso do Correio do Povo e do Jornal do Comércio que ajudaram a perceber os discursos de outros setores da sociedade, como os dos empresários, políticos e profissionais liberais a respeito do operariado, possibilitando analisar tanto as contradições quanto as aproximações desses discursos em relação à construção identitária proposta pela imprensa operária. Além disso, esses veículos também permitiram acompanhar o desenrolar de determinados fatos importantes, quando as fontes operárias rareavam ou desapareciam completamente. 
Isabel Bilhão

Finalmente, A Federação (analisada especialmente de 1906 a 1920), órgão do Partido Republicano Rio-Grandense e, por extensão, do Governo do Estado, onde se pôde perceber a voz "oficial" a respeito do movimento e das manifestações operárias na cidade.

Além desses jornais, que subsidiaram toda a investigação, optei por estudar as redes de relações, troca de informações, opiniões e circulação de idéias e pessoas, estabelecidas no interior do movimento operário europeu e brasileiro, a partir de informações encontradas em arquivos lisboetas.

Minhas atividades de pesquisa desenvolveram-se basicamente em dois fundos documentais: no Arquivo Histórico Social (AHS), que se encontra na Biblioteca Nacional de Lisboa, e no Espólio Pinto Quartim (EPQ), que se encontra no Instituto de Ciências Sociais da Universidade de Lisboa.

Essa opção de pesquisa justifica-se, em meu entendimento, pelo fato da cidade de Lisboa ter assumido, no período estudado, um importante papel de ligação entre o Brasil e a Europa, constituindo-se em um centro difusor de idéias e troca de informações. Nesse sentido, constatei que muitos dos documentos analisados (opúsculos, livretos e panfletos) eram traduzidos do francês, italiano, alemão e inglês para o português e espanhol, impressos nas gráficas de Lisboa e Porto e distribuídos tanto em Portugal e Espanha quanto no Brasil.

Os jornais operários portugueses, notadamente os anarquistas, também se preocupavam em manter colunas de informações sobre o que ocorria no movimento operário em diversas partes do mundo, cabendo destacar que tanto os militantes brasileiros utilizavam-se largamente desses veículos para fazerem chegar à Europa informações acerca do movimento operário e denunciar as arbitrariedades cometidas pelas autoridades brasileiras - sendo comum a solicitação, por parte da imprensa portuguesa, da divulgação dessas notícias pelos demais jornais operários europeus quanto, da mesma forma, os escritos produzidos por militantes e 
Identidade e trabalho: considerações sobre as relações...

teóricos do movimento operário europeu chegavam ao Brasil, provenientes de Portugal.

Uma das vias privilegiadas dessa circulação de idéias era, para o caso de Porto Alegre, o intercâmbio com os periodistas portugueses responsáveis pela publicação dos jornais Novos Horizontes, de Lisboa, ou $A$ Vida, do Porto, que eram divulgados pelo grupo editor d'A Luta. Além disso, os militantes locais faziam freqüentes referências de seus contatos com grupos portugueses, como o libertário Ação Direta, de Lisboa.

É inegável que tal possibilidade de contato, ainda que indireta, com todos esses textos possa ter provocado nos operários porto-alegrenses, por um lado, aquilo que Evaristo de Moraes chamou de "porre ideológico" (Moraes Filho, 1991, p. 37), ocasionado pela leitura de pensadores tão diversos como Marx, Proudhon, Bakunin, Lassalle, Engels, Benoît Malon, Eliseu Réclus, Tolstoi, Lombroso, Max Nordau, ou, principalmente, de seus resenhistas e comentadores. Mas, por outro, deve-se levar em conta, primeiro, que essa não é uma característica exclusiva dos grupos operários brasileiros e sim a forma marcante de como ocorreu a difusão do pensamento social do século XIX em várias partes do mundo e, segundo, que - embora essa leitura pudesse estar perpassada por um entendimento "desigual e difícil" - penso ser possível dizer que, quando apropriada pelos operários, acabou por servir-lhes de base para um processo de identificação, não apenas em relação a seus colegas mais próximos, mas também com aqueles que, em outras partes do mundo, passavam por situações semelhantes de exploração e luta, ajudando a difundir um sentimento de pertencimento e solidariedade ao "operariado universal".

Assim, mesmo considerando todos esses riscos e, além deles, o fato de existir, no período em estudo, uma elevada incidência de analfabetismo - representando um obstáculo importante às idéias divulgadas na imprensa - penso ser possível analisar, ainda que de forma indireta e indiciária, através das referidas fontes, as 
principais características presentes na construção identitária dos trabalhadores porto-alegrenses.

Nesse sentido, recorro novamente às considerações de Thompson, quando ele observa, em seu Formação da Classe Operária Inglesa, que o autodidatismo dos trabalhadores é um dos fatores preponderantes na dinâmica do fazer-se classe operária, exemplificado com suas constatações de que "um sapateiro, que aprendera a ler pelo Antigo Testamento, ia se aperfeiçoar com a Idade da razãa" e de que "diaristas analfabetos nem por isso deixa-

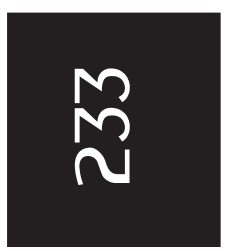
vam de ir, todas as semanas, a um bar onde lia-se em voz alta e discutia-se o editorial de Cobbett"; podia-se ler igualmente nas pensões operárias ou em reuniões políticas (Thompson, 1987, V. III, p. 304); e também, ainda segundo o historiador inglês, a preocupação com a informação gerou nos trabalhadores, de diversas categorias, a necessidade de organizar clubes de leitura e escolas, o que motivou pensadores radicais a disputar o público leitor com as sociedades cristãs.

Essas constatações mostram, na percepção de Thompson, que o autodidata tinha "muitas vezes um entendimento desigual e difícil, mas [que] era seu”. Após a leitura em grupo, fazia-se uma discussão. Assim, os articulistas buscavam expressar seus argumentos "o mais diretamente possível", mas os tecelões, malharistas ou sapateiros discutiam e interpretavam-nos a seu modo. Dessa forma, as idéias dos diferentes pensadores, ao chegarem ao público, deixavam de pertencer a eles (Thompson, V. III, p. 366-367).

Tomei de empréstimo essas considerações de Thompson porque me pareceu possível observar um fenômeno semelhante guardadas as proporções e características locais - em relação aos trabalhadores porto-alegrenses. Assim, as lideranças operárias publicavam textos próprios ou traduzidos de outras partes do mundo, procurando falar o mais diretamente possível a seu público, mas, ao circularem pelas rodas de leitura e discussão, entre os diversos grupos operários da cidade, esses textos deixavam de 
Identidade e trabalho: considerações sobre as relações...

pertencer a quem os escrevia. Eram lidos por alguém, discutidos, interpretados e reinterpretados por outros tantos, produzindo resultados muitas vezes diferentes do esperado por quem os publicou, mas, de qualquer forma, influenciando na construção das características identitárias daqueles operários que tivessem acesso a eles.

Além disso, não se pode desconsiderar o fato de que as livrarias, juntamente com outros espaços, como as redações de jornais, os bares e os cafés, funcionavam como locais de leitura, troca de idéias e discussões. Os bares serviam inclusive como locais de contribuição, através de listas de subscrições, para a manutenção dos periódicos ${ }^{6}$.

Estudos precedentes já demonstraram a importância dos bares e cafés como locais de debates e sociabilidades. Adhemar Lourenço destacou, por exemplo, o sentimento de fidelidade que identificava as diversas categorias profissionais, cada qual com o "seu" café. Assim, "os caixeiros freqüentavam o América aos domingos", já os gráficos freqüentavam o café Ferro Carril; essa fidelidade parecia ser levada a sério também pelo restante da comunidade e mesmo pelo Poder Judiciário, uma vez que o bar podia funcionar como o "endereço" de alguém, servindo inclusive para que "oficiais de justiça intimassem réus de processos" (Silva Jr., 1994, p. 158).

Portanto, parece-me ser defensável a idéia de que nas escolas, nas salas de leitura, nos bares, nas livrarias e em outros pontos de encontro menos ortodoxos (como, por exemplo, a alfaiataria do militante anarquista Stefan Michalski ${ }^{7}$ ), espalhados pela Porto Alegre do início do século XX, os textos, discursos e exemplos do movimento operário de outras partes do Brasil e do mundo podiam encontrar um público que não apenas participava das discussões, mas que também servia como multiplicador de idéias.

Além das fontes jornalísticas, também trabalhei com dois processos-crime: um deles instaurado após tumulto ocorrido durante uma greve encabeçada pelo Sindicato dos Calceteiros e Classes 
Anexas $^{8}$, em 1917, e outro instaurado em 1919, em decorrência de um assassinato praticado durante uma greve dos padeiros?

Mesmo levando em consideração o filtro estabelecido pela linguagem jurídica da época e a excepcionalidade dos fatos tratados - uma vez que esse tipo de documento só é produzido quando as normas legais são quebradas - penso que a riqueza das informações neles contidas justificou sua utilização, especialmente porque permitiram nomear os personagens envolvidos e conhecer, ao menos em parte, características de sua vida cotidiana.

O processo de 1917, para apurar o tumulto e a morte de um operário, foi instaurado contra vários réus, sendo o principal deles o espanhol Longuinho Monumento. Entretanto, entre vítimas e depoentes, passaram na época, pela Delegacia de Polícia do $1^{\circ}$ Distrito, mais ou menos 65 pessoas. A partir das informações contidas nos vários depoimentos, foi possível estabelecer alguns parâmetros de análise, observando, entre outras, as relações entre o grau de profissionalização e as origens étnicas e/ou nacionais dos depoentes, as possíveis rivalidades entre trabalhadores brasileiros e estrangeiros e os comportamentos considerados honrosos e desonrosos no decorrer do movimento grevista.

O outro processo, de 1919, tinha como réu um jovem padeiro chamado Leopoldo Silva, acusado de emboscar e matar a tiros um colega que não havia aderido a uma greve de sua categoria. Esse caso oferece uma série de informações interessantes que ajudam a perceber algumas características das vivências operárias da época, entre elas o entrelaçamento dos códigos de masculinidade e lealdade ao movimento operário, ou seja, as inter-relações entre as identidades de gênero e de operário.

Esses são os principais aspectos da construção identitária por mim enfocados. Reconheço, entretanto, que muitos outros foram deixados de lado, dentre eles, alguns que poderão, no futuro, interessar a outros pesquisadores que venham a se debruçar sobre o tema. Apenas a título de exemplo, cito, especialmente entre as 
Identidade e trabalho: considerações sobre as relações...

lideranças anarquistas, a difusão do Esperanto, que estudada mais profundamente e com novas fontes, provavelmente poderá esclarecer algumas facetas ainda pouco conhecidas da difusão do internacionalismo entre os operários locais.

Um outro aspecto, igualmente interessante para estudos vindouros, é o das ligações entre os grupos editores de Portugal e do Brasil, especialmente do Rio de Janeiro, que publicavam em parceria livretos, opúsculos e traduções de obras operárias. Essa investigação poderia ajudar a compreender melhor como ocorria a recepção e difusão do pensamento social europeu nas mais distantes localidades brasileiras. Nesse caso, ainda seria possível aprofundar essa observação tanto para Porto Alegre quanto para os outros pólos industriais do interior do Rio Grande do Sul.

Tal estudo demandaria um cruzamento de textos, correspondências e obras a ser realizado a partir de uma investigação mais aprofundada nos arquivos portugueses (especialmente em Lisboa e Porto), nas fontes deixadas pelo movimento operário do Rio de Janeiro, que se encontram no centro do país, bem como nos acervos locais.

Finalmente, considero que ainda se faz necessário um estudo mais aprofundado das relações identitárias do operariado porto-alegrense na década de 1920, observando as decorrências, no movimento operário local, das disputas ideológicas nacionais e internacionais ensejadas pela difusão do ideário comunista e pelos desdobramentos da Terceira Internacional.

Não tenho dúvidas de que esses são caminhos que ainda poderão apresentar muitas e gratificantes descobertas aos pesquisadores que vierem a se embrenhar por suas veredas e poderão brindar-lhes com novas possibilidades interpretativas, algumas poucas certezas, sempre provisórias e muitas novas interrogações - prêmio maior de todo aquele que optou por ocupar-se da pesquisa histórica.

Anos 90, Porto Alegre, v. 13, n. 23/24, p.215-240, jan./dez. 2006 


\section{Isabel Bilhão}

Recebido em 30/05/2006.

Aprovado em 02/08/2006.

\section{Identity and labor: considerations on identity relations in the world of labor, Porto Alegre City (1896-1920)}

Abstract: The present text has objective to reflect about the theoretical and methodical instrumental utility in my thesis, its aim analyzing the process of the identity construction of the porto-alegrense working class in the end of the XIX century and the first decades of the XX century. There are three hypotheses: 1 ) The construction of the working class identity demands searching for recognition through its pride of its productive capacity; 2) There are always social identities in relation, having mutual influences and contributing to permanent identity transformation; 3) The working class identity has not been built only from characteristics and from the context in which the worker are, but also from the combination of these characteristics with ideas, symbols and characteristics from many places that have been found in different countries.

Key-words: identity relationship - work - working class identity.

\section{Notas}

${ }^{1}$ A tese intitula-se Identidade e trabalho: análise da construção identitária dos operários porto-alegrenses (1896-1920), foi realizada sob a orientação da Prof ${ }^{a}$. Silvia Petersen e defendida em novembro de 2005 junto ao PPG-História da UFRGS.

${ }^{2}$ Especialmente THOMPSON, E. P. Formação da Classe Operária Inglesa. Rio de Janeiro: Paz e Terra, 1987. 3 volumes.

${ }^{3}$ Parece-me interessante lembrar que Thompson já havia reivindicado, no que se refere ao estudo da classe operária inglesa, esse mesmo cuidado com as "peculiaridades" locais, procurando romper com o esquema da "verdadeira" formação de classe em certo "estágio" do processo, reafirmando a necessidade de que a classe seja vista como algo que só se delineia no modo como as pessoas vivem e a partir de suas experiências, no interior de suas relações sociais, utilizando-se de uma metáfora para lembrar aos intelectuais que a classe não é "uma motocicleta cujo assento esteja vazio" sobre o qual estes possam saltar para, com sua verdadeira teoria, dar a direção correta (Thompson, 2001, p. 281).

${ }^{4}$ Versão mais ou menos generalizada para o uso do qualificativo "classes perigosas" em diferentes obras, ver, entre outros: para a Inglaterra, ENGELS, Friedrich. $A$ situação da classe trabalhadora na Inglaterra. São Paulo: Global, 1985 (especialmente o capítulo "As grandes cidades", p. 35-92); para a França: CHEVALLIER, Louis.

Anos 90, Porto Alegre, v. 13, n. 23/24, p.215-240, jan./dez. 2006 
Identidade e trabalho: considerações sobre as relações...

Classes laborieuses et classes dangereuses. Paris: Librairie Académique Perrin, 2002; para o Brasil: GUIMARÂES, Alberto Passos. As classesperigosas: banditismo urbano e rural. Rio de Janeiro: Edições Graal, 1981; CHALLHOUB, Sidney. Trabalho, lar e botequim: o cotidiano dos trabalbadores do Rio de Janeiro da Belle Époque. São Paulo: Brasiliense, 1986. (especialmente o capítulo "Sobrevivendo...", p. 35-111).

${ }^{5} \mathrm{O}$ que não significa que fizessem abertamente oposição ao governo, pois esse é o período da chamada ditadura Castilhista-Borgista.

${ }^{6}$ Nesse sentido, por exemplo, os redatores d' $A$ Luta mencionam e agradecem as colaborações recebidas no "café" ( $A$ Luta, 20/01/1911, p. 4).

${ }^{7}$ A alfaiataria do anarquista Stefan Michalski, que se localizava na Rua dos Andradas, era, pelo menos até 1930, um conhecido ponto de encontro de intelectuais e militantes (Marçal, 1995, p. 128).

${ }^{8}$ Processo-crime 856. Maço: 53, Estante 29. Réus: Longuinho Monumento \& outros, 1917 (APERS).

${ }^{9}$ Processo-crime 1029. Maço: 67, Estante 29. Réu: Leopoldo Silva, Porto Alegre, 1919 (APERS).

\section{Referências}

ARAVANIS, Evangelia. Leituras, edições e circulações de impressos na Porto Alegre de 1906 a 1911: uma análise a partir do periódico A Luta. História Unisinos, São Leopoldo: Revista do PPG em História da UNISINOS, v. 6, n. 6, 2002.

BACZKO, Bronislaw. Los imaginários sociales. Memórias y esperanzas colectivas. Buenos Aires: Nueva Vision, 1991.

BILHÃO, Isabel. Rivalidades e Solidariedades no Movimento Operário (Porto Alegre 1906-1911). Porto Alegre: EDIPUCRS, 1999.

BATALHA, Cláudio; SILVA, Fernando Teixeira da; FORTES, Alexandre (orgs.). Culturas de Classe: identidade e diversidade na formação do operariado. Campinas: Editora da UNICAMP, 2004.

BOURDIEU, Pierre. A identidade e a representação. Elementos para uma reflexão crítica sobre a idéia de região. In: . Opoder simbólico. Rio de Janeiro: Bertrand, 1989.

CIAMPA, Antônio da Costa. "Identidade". In: LANE, Silvia Tatiana Maurer; CODO, Wanderley (orgs.). Psicologia Social: O homem em movimento. São Paulo: Brasiliense, 1985.

Anos 90, Porto Alegre, v. 13, n. 23/24, p.215-240, jan./dez. 2006 
Isabel Bilhão

COSTA, Emilia Viotti da. Novos públicos, novas políticas, novas histórias: do reducionismo econômico ao reducionismo cultural: em busca da dialética. Anos 90, Porto Alegre: PPG em História da UFRGS, n. 10, dez. 1998.

HALL, Stuart. A questão da identidade cultural. Textos Didáticos, Departamento de Antropologia do Instituto de Filosofia e Ciências Humanas da UNICAMP, n. 18, $2^{\text {a }}$ ed., fev. 1998.

KIRK, Neville. Cultura: costume, comercialização e classe. In: BATALHA, Cláudio; SILVA, Fernando Teixeira da; FORTES, Alexandre (orgs.). Culturas de classe: identidade e diversidade na formação do operariado. Campinas: Editora da UNICAMP, 2004.

MARÇAL, João Batista Os anarquistas no Rio Grande do Sul; anotações biográficas, textos e fotos de velhos militantes da classe operária gaúcha. Porto Alegre: EU/ Porto Alegre, 1995.

MENDES, José Manuel Oliveira. O desafio das identidades. In: SANTOS, Boaventura de Souza (org.). A globalização e as Ciências Sociais. São Paulo: Cortez, 2002.

MORAES FILHO, Evaristo de. A proto-história do Marxismo no Brasil. In: REIS Filho et al. História do Marxismo no Brasil: o impacto das revoluções. Rio de Janeiro: Paz e Terra, 1991.

OLIVEIRA, Roberto Cardoso de. Identidade, etnia e estrutura Social. São Paulo: Livraria Pioneira Editora, 1976.

PETERSEN, Silvia; LUCAS, Elisabeth. Antologia do movimento operário gaúcho (1870-1937). Porto Alegre: Mercado Aberto, 1992.

PETERSEN, Silvia. Que a União Operária Seja Nossa Pátria! História das lutas dos operários gaúchos para construir suas organizações. Santa Maria: Ed. da UFSM; Porto Alegre: Ed. da UFRGS, 2001.

POLLAK, Michael. Memória e identidade social. Estudos Históricos, Rio de Janeiro: CPDOC/FGV, v. 5, n.10, 1992.

SAVAGE, Mike. Classe e História do Trabalho. In: BATALHA, Cláudio; SILVA, Fernando Teixeira da; FORTES, Alexandre (orgs.). Culturas de classe: identidade e diversidade na formação do operariado. Campinas: Editora da UNICAMP, 2004. p. 25-48. 
Identidade e trabalho: considerações sobre as relações...

SCHMIDT, Benito. O patriarca e o Tribuno: Caminhos, encruzilhadas, viagens e pontes de dois líderes socialistas - Francisco Xavier da Costa (187?-1934) e Carlos Cavaco (1878-1961). Tese de Doutorado, Universidade Estadual de Campinas, Campinas, 2002.

Em busca da terra da promissão: A história de dois líderes socialistas. Porto Alegre: Palmarinca, 2004.

SILVA JR, Adhemar Lourenço. "Povo, trabalhadores": tumultos e movimento operário (estudo centrado em Porto Alegre, 1917). Dissertação de Mestrado, IFCH/UFRGS, Porto Alegre, 1994.

THOMPSON, E. P. La sociedad inglesa del siglo XVIII: ¿Lucha de clases sin clases? In: . Tradición revuelta e consciencia de clase: Estudios sobre la crisis de la sociedad preindustrial. Barcelona: Editorial Crítica, 1979.

volumes.

Formação da classe operária inglesa. Rio de Janeiro: Paz e Terra, 1987. 3

As peculiaridades dos ingleses. In: NEGRO, Antonio Luigi; SILVA, Sergio (orgs.). E. P. Thompson - As Peculiaridades dos ingleses e outros artigos. Campinas: Editora da Unicamp, 2001.

Anos 90, Porto Alegre, v. 13, n. 23/24, p.215-240, jan./dez. 2006 